Revista Iberoamericana, Vol. LXIX, Núm. 202, Enero-Marzo 2003, 119-135

\title{
RECORDANDO CON IRA: ESTRATEGIAS IDEOLÓGICAS Y FICCIONALES ARGENTINAS A FIN DE SIGLO
}

POR

Andrés Avellaneda University of Florida-Gainesville

En materia de literatura, la historia — la política, la "realidad”-, interesa más por su modo de relacionarse con las elecciones discursivas y formales de los textos que por su poder de convocar en ellos enconos o amores temáticos e ideológicos. Las escrituras de punta cuestionan antes que nada los usos de la lengua, y es por esa vía regia que cuestionan los saberes, incluso los político-ideológicos. Por eso mismo, lo distintivo de una escritura no suele encontrarse en los temas sino en los discursos; el trabajo de escribir no se concentra en investigar los mandatos ideológicos, sino en explorar la potencialidad de los lenguajes. El objeto de análisis será pues en este trabajo la discursividad (ficcional, poética) de lo histórico-político en la literatura argentina de fin de siglo, más que su presencia en ella como elemento meramente referencial o temático. Examinados desde esta perspectiva, los contactos entre historia, política y literatura muestran tres momentos importantes en la Argentina contemporánea, en orden cronológico: la década del treinta, el peronismo, y el ciclo de dictaduras y redemocratización ocurrido en los últimos treinta años del siglo veinte. En estas zonas de gran intensidad histórica, ciertos instrumentos discursivos de la literatura argentina articulan varias estrategias retóricas que definen otros tantos modos de significación ideológica. Hacia 1930 Arlt inscribe en sus relatos el efecto de desfamiliarización, con el que desnaturaliza las instituciones y los valores establecidos. Entre las décadas del cuarenta y cincuenta, Borges, y Borges-Bioy como coautores, aclimatan un discurso cuyo sentido debe ser descodificado en la lectura para que funcionen, por reposición, ciertos códigos que están ausentes en el texto. Entre las décadas del sesenta y del noventa ese discurso de descodificación es trabajado, primero, para resignificar el sentido por inversión de los códigos, y luego para que la oposición entre códigos disímiles — la condición básica de la operación descodificadora—quede borrada en los textos y pierda así validez la existencia misma de la diferencia como categoría escritural (e ideológica, en consecuencia). La "broma literaria” con la que Borges y Bioy irrumpen desembozadamente en lo político es sólo una hipérbole exasperada de un modo que la escritura borgeana venía preconizando desde la década anterior, y que iba a hacerse célebre en sus textos "serios" posteriores. Pero acaso por la crudeza misma de los relatos conjuntos, el recurso de descodificación se hizo más visible en ellos y por lo tanto más fértil para generar una descendencia discursiva. Es a partir de esa estrategia borgeana de los cuarenta y cincuenta que la narrativa argentina trabaja “ideológicamente” sus discursos en 
la década siguiente: primero, como en Germán Rozenmacher, invirtiendo semánticamente — de negativo a positivo — el valor de los dos códigos opuestos; y luego, como en Manuel Puig, anulando la oposición sémica misma con un discurso de mezcla. La alusividad y la alegorización pasan a ser estrategias predilectas de la ficción argentina en los siguientes treinta años del siglo, sobre todo cuando la voluntad del decir ideológico ocupa buena parte de la enunciación y del enunciado.

1. De Arlt a Puig: desfamiliarización, descodificación, mezcla

La década del treinta es obvia en los textos de Arlt no porque sus relatos hayan reflejado los sacudimientos políticos y sociales de la época, sino porque se insertaron estratégicamente en un lugar saturado por los mitos culturales de la pequeña clase media urbana, cediendo a esos lectores la responsabilidad final de producir los sentidos ficcionales. Son textos que actúan políticamente en el sentido gramsciano de la "lucha del arte por una nueva cultura”, abriendo a sus lectores la percepción de lo que les es difícil o imposible ver en el transcurrir de la vida cotidiana. Como los de Brecht en la Alemania coetánea, los textos arltianos aclimatan en la literatura argentina el efecto de desfamiliarización por el cual las instituciones y las conductas habituales, al "hacerse extrañas”, quedan forzosamente expuestas a una nueva comprensión crítica durante el escrutinio de la lectura: el discurso ficcional iguala prácticas ilícitas e inmorales con prácticas aceptadas como normales, y éstas quedan investidas de la condenación ética y política que a aquellas le correspondían (en el discurso del Rufián Melancólico, por ejemplo, el prostíbulo es el modelo de la sociedad establecida). Saturados de doble discurso, los relatos de Arlt son ideológicos — hablan de historia y política-, porque activan dentro de sí mismos la experiencia social y cultural de los lectores coetáneos, abriendo en ese espacio dos sentidos maestros que iban a ser fundamentales en la posterior ficción argentina: el de inestabilidad y desequilibrio (ligado a ruptura, cambio, catástrofe inminente); y el de ubicación ambigua entre dos zonas, el estar-en-el-borde (relacionado con deslizamiento, caída, destrucción, y también con los significados opuestos de salvación y acceso, entendidos como salto cualitativo o como solución milagrosa de la aporía que plantea el límite y la catástrofe). Son textos que abren un proceso de significación ideológica posible; y que prueban también que el texto literario puede ser una vía regia hacia la actualización de "mensajes ideológicos" sin tener que incurrir necesariamente en la ilusión mimética, en la seducción del referente, en el paradigma realista-naturalista. ${ }^{1}$

\footnotetext{
${ }^{1}$ En lo expresivo, la desfamiliarización produce un borrado de bordes genéricos y discursivos que facilita la fusión de lo high brow con lo low brow. Descreer de lo creído, creer en lo increíble, desconfiar de la tradición genérica - los efectos del recurso socavan la certidumbre y propician los típicos dobles discursos arltianos (donde se hacen eco los sentidos del "mundo al revés", la mezcla caótica de distintos niveles que abunda en una rica tradición de cuño popular-medieval, activada a su vez en la letra de muchos tangos celebrados coetáneamente por los lectores de Arlt: por ejemplo en "Cambalache”, la letra emblemática de Discépolo). Cuarenta años después Manuel Puig trabaja esos efectos arltianos con el material del cine y del habla popular y los transmite, así reciclados, a los escritores jóvenes de los ochenta y los noventa.
} 
En las décadas del cuarenta y del cincuenta, la escritura de Borges (y la de Borges con Bioy) es ideológica, es histórica y política — “antiperonista”-, porque establece un pacto de lectura que requiere la reposición de sentidos que están ausentes en el texto pero que están presentes en los códigos de los lectores: un discurso que vive de otros discursos donde circulan oposiciones (civilización y barbarie; silencio y ruido; armonía y conflicto; certidumbre y confusión), cuya aceptación previa garantiza el éxito de la operación descodificadora. ${ }^{2}$ Estas prácticas aclimatan en la literatura argentina una estrategia o “poética de adivinación”, en que la conexión referencial (ideológica) depende de un pacto de lectura específico que se cumple cada vez que la lectura logra suplir la ausencia de los códigos y los referentes duros del relato. La estrategia se expande hacia otros recursos retóricos que dominan en la serie "antiperonista” de Borges y Bioy: la parodia, o sea la ruptura de un sistema por otro que es sugerido por negación y que está fuera del texto; la figura de contradicción, que se construye por medio de dos enunciados diferentes que exigen el rechazo de un sentido que es superficial y la aceptación de otro que es verdadero o profundo; la forma de relato policial, que funciona como una síntesis del sistema por la técnica misma que aplica: despejar una incógnita ausente, resolver el enigma planteado por la verdad oculta. Los topoi literarios “antiperonistas” (el de la invasión fue el más reiterado) existen simultáneamente en el plano de competencia tanto del escritor como del lector; en términos semiológicos, coinciden los sistemas de expectativas de emisores y receptores, y el signo ideológico — por ejemplo, el "dictum antiperonista"— puede ser repetido en diferentes textos y por diferentes escrituras porque existen códigos culturales que son compartidos por ambas partes del circuito. Por ejemplo, en los cuentos que Cortázar escribe desde 1945 y recoge en Bestiario, de 1950; sobre todo en “Casa tomada”, donde lo invasor es un hueco, una ausencia lista para ser suplida por la lectura competente de esos años.

Si en "Casa tomada” lo invasor como hueco generaba un relato ausente listo para ser suplido por los lectores competentes de 1945, la reescritura que de ese relato hace Germán Rozenmacher dieciséis años más tarde en su cuento “Cabecita negra” (1961), consiste en llenar el hueco con la identidad concreta del policía proletario y mestizo que irrumpe en el orden doméstico del propietario blanco de clase media. Esta resignificación del topos es posible gracias a la inversión de los códigos y de las representaciones ideológicas; por obra de esa inversión, los atributos de la barbarie —el desorden, el ruido,

\footnotetext{
${ }^{2}$ En un temprano ensayo de 1927, “La postulación de la realidad”, Borges defiende con elocuencia la teoría de que la verosimilitud de un relato debe depender de sus silencios y omisiones, de lo que no está presente en el texto; en sus propias palabras, de "una realidad más compleja que la declarada al lector”. Más que irrealidad en la ficción, Borges propone lo real por omisión y por ausencia, como en el comienzo de “Tlön, Uqbar, Orbis Tertius”, de 1941: “Bioy Casares había cenado conmigo esa noche y nos demoró una vasta polémica sobre la ejecución de una novela en primera persona, cuyo narrador omitiera o desfigurara los hechos e incurriera en diversas contradicciones, que permitieran a unos pocos lectores - a muy pocos lectores- la adivinación de una realidad atroz o banal” (Obras completas 431). La práctica de esa poética de la adivinación, de la conexión referencial por medio del acto de lectura, recorre buena parte de la ficción borgeana y está sin duda presente en textos suyos que sólo por medio de una "adivinación” de los lectores hablan elocuente y apasionadamente sobre política, sobre el peronismo por ejemplo.
} 
el salvajismo- son despojados de negatividad, la idea de orden queda trastocada y la moral pequeño-burguesa pasa a ocupar ahora el lugar de la barbarie. ${ }^{3}$ La narrativa joven del sesenta está, ideológicamente, en las antípodas del modelo borgeano de los cuarenta y cincuenta, pero echa mano de su aparato retórico para hablar (de) la historia. Lo que se muestra en la inversión de los topoi practicada por Rozenmacher es la presencia de nuevas representaciones ideológicas de distinto signo: el tránsito desde los Ernst Cassirer, Pierre Lèvy-Bruhl y James Frazer de los cuarenta, al Frantz Fanon y al Albert Memmi de los sesenta; el pasaje desde la idea de mentalidad primitiva a la idea de mentalidad colonizada; el trayecto que va desde la creencia en una comunidad universal interpretativa a la revelación de la lucha cultural entre centros y periferias ubicados tanto entre naciones diferentes como por dentro de las naciones mismas. En los sesenta y setenta la nueva generación se propone trasladar el peronismo histórico y el peronismo coetáneo más allá de los debates locales para incluirlos como un episodio más en las luchas culturales y políticas de los pueblos colonizados. Entre tanto, los narradores que publican sus primeros libros en esos años heredan (y utilizan con astucia retórica) los pasajes entre sistema literario y sistema ideológico que habían elaborado los escritores liberales antiperonistas durante las dos décadas previas. Si en lo político los nuevos del sesenta proponen reexaminar críticamente el peronismo sin los traumas de rechazo propios del pasado, en literatura estipulan la reelaboración de los lenguajes, los sentidos y las prácticas que se conectan con ese tipo de reexamen. Porque son escritores, se preguntan qué hacer con los recursos de los grandes textos que preceden a los suyos: qué hacer — aunque se quiera rechazar su "mensaje" - , con la reposición de lo ausente hecha célebre por los textos de Borges, y de Borges con Bioy Casares.

Si la inversión del topos y del código requiere sustituir un campo semántico por otro, tal operación exige a su vez preservar retóricamente la existencia y la validez de ambos campos por separado: el sema "cabecita negra” pudo ser invertido y adscrito al semema “civilización”, sólo porque "civilización” y "barbarie” seguían pensadas y reconocidas como campos semánticos válidos. El paso siguiente se da poco después en la ficción de Manuel Puig: mezclando residuos de la cultura de masas con discursos de saberes prestigiosos, o filamentos de historias orales de vida con falsa documentación escrita, sus relatos harán posible un texto que es y no es texto simultáneamente; que está al mismo tiempo en el centro y en el borde de los géneros; que es tanto inventio como reproductio, creación y copia; que, narrado y firmado, niega la existencia del sujeto que lo produce. Un discurso de fusión y mezcla que se hace posible porque se cree que las oposiciones sémicas no son pertinentes: que lo alto no se opone a lo bajo, ni lo culto a lo popular, ni lo masculino a lo femenino, ni lo bárbaro a lo civilizado; que la “oposición” de los campos semánticos, en suma, no existe, y que ambos son, por consiguiente, intercambiables; y que la escritura es, en definitiva, una práctica de deslizamientos y pasajes. Todo esto escandaliza y perturba, porque si se postula la ruptura de la diferencia (la oposición sémica), si se desesencializa la noción de categoría sémica, se termina por desconstruir — discursivamente — la ideología de naturalización que garantiza la estabilidad de un

${ }^{3}$ El modelo retórico de inversión de los códigos se instala con vigor en la ficción argentina. Diez años más tarde, en su relato de 1973 "El niño proletario”, Osvaldo Lamborghini lo emplea para trabajar con "El matadero" de Esteban Echeverría. 
"modo de vida" o de un "ser nacional” considerados inamovibles. Es por producir ese sentido por dentro mismo del discurso literario que los relatos de Puig que comienzan a circular a fines de los sesenta hablan subversivamente la literatura (y la historia y la política). ${ }^{4}$

\section{RelatAndo EL Fin DE SIGLO}

Durante la dictadura de 1976-83, esta tradición discursiva trabajada durante tres décadas anteriores garantizó la continuidad de un posible político en el habla literaria. Escribir ficción durante el Proceso fue ante todo reconstruir un sentido ante la pérdida impuesta del sentido, proponer un discurso sobre cómo narrar una H/historia. Sobre todo la "poética de adivinación” borgeana — la trampa persuasiva para proveer el código ausente-, y en menor grado las técnicas de inversión y de borrado de los códigos practicadas desde Rozenmacher hasta Puig, proporcionaron la ferretería retórica necesaria para hablar en tiempo de silencio: resumidamente, sus recursos de transferencia semántica, tanto los metonímicos como los metafóricos (simbólicos, alusivos, alegóricos). El presente indecible aparece así en estrategias alusivas donde una noción implícita —como el asesinato, la tortura o el terror ubicuo-, es conectada con referencias explícitas de otro orden, como la imagen del holocausto nuclear, o el modelo de vivir en tránsito y en frontera (Copyright, de Juan Carlos Martini Real, 1979); el hospital donde un paciente se enfrenta a poderes implacables (Soy paciente, de Ana María Shúa, 1980); el ámbito donde ocurren misteriosos asesinatos de caballos (Nadie nada nunca, de Juan José Saer, 1980); una geografía imaginaria donde impera el sometimiento (El vuelo del tigre, de Daniel Moyano, 1981); un prostíbulo donde se lucha por el poder (La vida entera, de Juan Martini, 1981). El enigma preside el sistema retórico de estos relatos, con la operación de desciframiento en lugar central: en Respiración artificial (1980), la novela de Piglia que es emblema de estos años, son los secretos encubiertos en cartas, papeles, libros, conversaciones. El relato de investigación, con su pacto de lectura en clave, reaparece en consecuencia. ${ }^{5}$ Como en la década del cuarenta, esta retórica convoca a su lector implícito para que adivine sentidos ocultos, pero con una enorme diferencia acotada por dos situaciones nuevas: si había una audiencia homogénea para encargarse de la tarea descodificadora, ésta era ahora de otro tipo, ubicada definitivamente en las antípodas ideológicas del cuarenta; esa nueva audiencia era, además, dadora de desaparecidos.

\footnotetext{
${ }^{4}$ Por ese camino abierto por Puig para desnaturalizar y desesencializar discursivamente llega una década después el bricolage a lo César Aira, cuyos relatos, trabajando con retazos de la tradición literaria y con la lengua de la traducción, tienen el efecto de borrar la nitidez y estabilidad tanto de los géneros como de los objetos sometidos a la representación y los conceptos subyacentes a los temas.

${ }^{5}$ Dice Feinmann sobre su novela Últimos días de la víctima: "En el [19]76 yo iba a editar mi libro Filosofía y nación pero a partir del golpe militar no se podía publicar nada que oliera mínimamente a intercambio de ideas. Entonces pensé que algo tenía que escribir, pero algo que diera testimonio de lo que había padecido mi generación: la violencia desenfrenada. Y aparece la novela policial; en ella el crimen es inherente al género, el asesinato forma parte de su legalidad interna. Es el género ideal para hablar del crimen y la violencia” (Ventura 2).
} 
La persistencia de los modos discursivos con que la narrativa argentina había manejado su relación con lo histórico, lo ideológico y lo político desde Arlt en adelante, se hace evidente al cesar la dictadura. Cuando se apostaba a un hipotético decir "lo real" con la simplicidad mimética que había sido imposible durante los años de represión, los nuevos narradores del ochenta negaron encarnizadamente, con pocas excepciones, que la literatura debiera subordinarse a una "política de lo real”. ${ }^{6}$ Para ellos, escribir ficción fue antes que nada reemplazar el “contenido” (el tema, el género) por la escritura; el significado por el significante; que lo "ideológico” convocara la atención hacia sí mismo, más como discurso que como mensaje. Si la escritura era lo prioritario, escribir narrativa consistió entonces en vaciar el género; trabajar en sus límites y reescribir en sus "bordes”; teorizar sobre lo ficcional desde adentro del relato; reproducir discursos; trabajar con la traducción, la cita, la copia, los saberes robados y parodiados: exaltar, en suma, la bastardía y la mezcla. Consecuentemente, los nuevos reconocieron en la ficción de Puig las marcas de origen, declarándose casi unánimemente como descendientes suyos. ${ }^{7} \mathrm{Y}$ al reconocerse en ese linaje suscribieron el mismo modo de producción de significado subversivo que Puig había activado veinte años antes: por la vía regia de la mezcla escritural llegaron al borrado de oposiciones; a la elisión de la diferencia; al desmontaje, por último, de la ideología naturalizadora. De esa manera, la proclamada "hiperliterariedad” y autorreferencialidad de los nuevos ochentistas no resultaba tan "apolítica” como pareció en esos momentos. Los nuevos mostraron la perduración de ese "modo Puig” de decir lo histórico y lo político tanto en sus ficciones como en las operaciones de canonización de la breve obra que había escrito Osvaldo Lamborghini desde fines de los sesenta hasta su muerte en 1985. Como Puig, Luis Gusmán o Héctor Libertella, Lamborghini practicaba en sus textos una estética de mezcla; pero, además, había recogido los materiales y retazos de su escritura en las hablas del juego infantil, de la historieta, de lo erótico-sexual; sobre todo los había recolectado en las jergas políticas del peronismo histórico, con lo cual había logrado lo que era poco menos que impensable en los fervorosos sesentas: trabajar lo político como escritura en vez de usar lo político como tema (según el modo preconizado por el realismo crítico que pujaba entonces por la hegemonía); y ello en medio del caldeado debate sobre el nuevo prestigio del peronismo. Con esa suerte de populismo estético que incorporaba el kitsch y la cultura de masas, Lamborghini abría un modo posible de

\footnotetext{
${ }^{6}$ Son en ese momento narradores jóvenes los que tenían alrededor de veinte años cuando se inicia en 1976 la dictadura. A mediados de los ochenta ingresaron decididamente en el debate sobre las relaciones entre ficción, realidad, historia e ideología. Véanse Alan Pauls: "Prefiero una literatura que profundice en lo real y no que la siga como un perro” (Warley 39); y Daniel Guebel: "Lo políticosocial opera en la literatura, pero sé también que las vacías teorías del reflejo no pueden dar cuenta de nada” (Muleiro: "Daniel Guebel” 26).

${ }^{7}$ Se publican por entonces los primeros ensayos sobre Puig de los más jóvenes (como el de Alan Pauls sobre La traición de Rita Hayworth). Y la muerte de Borges (1986) sobreviene en medio de la enérgica arremetida parricida a cargo de esos mismos jóvenes. Véase Sergio Chejfec: "Hasta nuestro escritor ejemplar por excelencia, cuyas letras del apellido son ya las únicas seis que se utilizan para hacer los fideos de letras para la sopa, no se conformó con reflexionar: quiso enseñar las dudas con todo su penoso cursillo metafísico plagado de espejitos, citas y simetrías" "Narrativa” 5); Matilde Sánchez: “[Estoy] harta de la monorreferencia. Manuel Puig es el anti-Borges y creo que la literatura actual va en esa dirección” (O’Donnell 7).
} 
reconexión con la identidad social. No en el lugar sacralizado por las expectativas institucionales de la política, sino en el margen; haciendo que su hablante desencajado profiriera un habla procaz, desmesurada, escatológica, para que lo "bárbaro" de la vieja ecuación ocupara y asumiera la totalidad del lenguaje posible: totalizando la barbarie, en suma, como única opción. Ese estar-en-el-margen producía un efecto ideológico similar al que había buscado Rozenmacher con la inversión del topos antiperonista; pero por el lado retórico se emparentaba además con el borrado de la diferencia hecha por Puig. Como él, Lamborghini descreía de las oposiciones sémicas y lo demostraba discursivamente fusionándolas entre sí, mezclando las dicciones en una koiné de hablas altas y bajas que ocupan todo el lenguaje posible. Como en Puig, en Lamborghini lo político aparecía discursivamente; pero activando lo ideológico en los sintagmas con que la comunidad misma había materializado su inserción en la historia de los cuarenta y los cincuenta.

Al poner a Puig y a Lamborghini a la cabeza de su canon, los nuevos narradores de la posdictadura definieron un tono ideológico y político que iba a ser específico poco más tarde en la escritura de los noventa, un tono definido por el trabajo con los bordes discursivos de los mitos argentinos y por el postulado retórico de que narrar es abrir a la comprensión los discursos sociales borrosos y titubeantes. El "comentario sobre lo real” que se fue imponiendo en la última década del siglo consistió sobre todo en trabajar con la memoria social, a propósito de mitos culturales, históricos y políticos profundamente arraigados en la historia argentina pasada o reciente. Y a la cabeza de todos los mitos disponibles estaban naturalmente los del peronismo, sobre todos los convocados por la figura de Evita. ${ }^{8}$ En un breve texto suyo de 1960, "El simulacro”, Borges había sellado el mito de Eva encerrándolo en el marco final del cadáver; ${ }^{9}$ poco después, ese topos borgeano comienza a ser invertido con versiones que pasan desde esa Eva cadáver de cierre a una Eva que aun como cadáver es apertura a una fuerza sin límite. Eva literaria es así un enigma que debe ser resuelto, un cadáver que debe ser encontrado y resemantizado, y en ese

\footnotetext{
${ }^{8}$ Varios relatos que en los últimos veinte años trabajan los discursos míticos del peronismo constituyen una suerte de familia textual. Entre ellos, la novela de Luis Gusmán En el corazón de junio (1983), donde la clausura del primer peronismo el 16 de junio de 1955, se trabaja como un mito trágico-elegíaco entre una agonía física y una agonía literaria (es decir como lucha hacia un desenlace textual). En La novela de Perón (1985) y en Santa Evita (1995) Tomás Eloy Martínez trabaja los mitos peronistas como acceso onírico a la historia nacional. En su novela Roberto y Eva (1989) Guillermo Saccomano explora los cruces de mitos literarios “altos” y "bajos”, la mixtura de El juguete rabioso con La razón de mi vida. En su novela El muchacho peronista (1991) Marcelo Figueras trabaja los sentidos de reproducción y posteridad por dentro de la versión peronista del mito del gran macho poderoso. En Una pálida historia de amor (1991) Rodolfo Fogwill trabaja la etapa lopezrreguista, el momento del segundo crepúsculo otoñal del peronismo, como así también Luis Gusmán en Villa (1995), donde se comprimen los requechos de la gloria peronista por dentro de la degradación de sus símbolos y discursos en los violentos mediados del setenta.

${ }^{9}$ En "El simulacro" los muchos velatorios que hicieron las clases populares en 1952 con motivo de la muerte de Eva Perón se compendian dentro de un humilde rancho en un villorio del Chaco. El funeral es allí una farsa donde todo está falsificado - “El enlutado no era Perón y la muñeca rubia no era la mujer Eva Duarte” —, porque en todo caso "tampoco Perón era Perón ni Eva era Eva” (Obras completas 789), con lo cual se cierra la curva: el funeral no existe porque tampoco existió Evita (doblemente negada en el texto al ser Eva Duarte, y no Eva Perón).
} 
espacio es donde los textos de Rodolfo Walsh, de David Viñas, de Mario Szichman, de Tomás Eloy Martínez, de Rodrigo Fresán, plantean la fuerza potencial y perturbadora del cadáver, su poder para movilizar y cambiar conductas: personales, políticas, estéticas y, por supuesto, textuales. ${ }^{10}$ Pero el texto Eva avanza otro paso, borrando la marca del cadáver para reescribirlo como cuerpo vivo proveedor. ${ }^{11}$ Es la Eva de la narrativa argentina de los noventa: una Eva viva a veces sin nombre propio y otras veces convocada vicariamente en personajes hechos a su imagen y semejanza, o en Evas que son previas a la Eva conocida. En la novela La construcción del héroe (1989) de Juan Martini, la heroína Beba Obregón - “esa mujer” en el texto, en clara intertextualidad con Rodolfo Walshestá modelada sobre la Evita vigorosa que corrige injusticias. ${ }^{12}$ Una Eva que vive como una pre-Eva-que-busca-su-destino - tímida, pobre, pero dueña ya de toda su fuerza y sus convicciones futuras-, es la de Roberto y Eva (1989) de Saccomanno, donde Arlt y Eva se enamoran poco antes de que él muera en $1942 .{ }^{13}$ En la novela El muchacho peronista ni siquiera se trata de la ignota actriz Eva Duarte previa a la Eva que fraguara Saccomanno, sino de Potota, la primera mujer de Perón: una "pre-protoEva" que como grado cero de estos desplazamientos hace aún más claros los significados de vitalidad ideológica y política encarnados en la Evita que se desea circular en el texto. ${ }^{14}$ Esta Eva viva dadora de fuerza (de bienes y hasta de energía revolucionaria) es también la Eva desmesurada de Copi —en su pieza teatral “Eva Perón”, escrita en francés, publicada en París en 1969,

\footnotetext{
${ }^{10}$ En orden cronológico de publicación: Viñas, “La señora muerta”(1964); Walsh, “Esa mujer”(1964); Szichman, A las 20.25 la señora entró en la inmortalidad (1981); Martínez, La novela de Perón (1991); Fresán, “El único privilegiado” (1994); Martínez, Santa Evita (1995).

${ }^{11} \mathrm{El}$ architexto de referencia es el personaje construido oralmente por la Eva histórica en 1943-44 a partir de los guiones radiales que protagonizaba, fijado luego en La razón de mi vida de 1951, y finalmente redondeado en el discurso romántico-revolucionario de su último año de vida. Puig es quien explora por primera vez ese architexto, activando el imaginario reivindicatorio y la conciencia política de marginación en el capítulo "Diario de Esther, 1947” de La traición de Rita Hayworth (1968). Poco después, Leónidas Lamborghini (“Eva Perón en la hoguera”, 1972), y María Elena Walsh ("Eva”, 1976) inscriben en ambos poemas una Eva semejante, cuyo lugar de enunciación se ubica en el momento de su máximo vigor ideológico.

${ }^{12}$ Por ejemplo: “[H]asta la última puta jura que esa mujer se sacó su tapado de piel ... cuando ella estaba muerta de hambre, muerta de frío, y no tenía, para colmo, dónde caerse muerta ... que al verla en esas condiciones esa mujer le dio quinientos pesos ... y que luego, enternecida pero sin que su cara mostrase ni la más mínima indulgencia, se sacó el tapado de piel, se lo puso sobre los hombros ... y se perdió en las tinieblas de la noche, sola, alta y rubia, como una aparición” (116).

${ }^{13} \mathrm{O}$ sea poco antes de que empezara a existir la Eva histórica, que se actualiza en el intertexto con el deseo expresado diez años después en La razón de mi vida (dice la Eva de Saccomanno: "Quisiera que mi nombre figurase alguna vez en la historia...” 115); y en la fiereza de su apuesta personal y política: "Y si voy a seguir viviendo, se lo juro, es para que ninguna mujer y ningún hombre, en este país, sufran lo que sufrimos nosotros” (154).

${ }^{14}$ El asesinato de Perón en 1938, en un prostíbulo de Chile, deja a Potota/Eva sola en la historia: será Eva, no Perón, quien entre en la Historia. Es la Eva que también destella en la pieza teatral Evita y Victoria (1990) de Mónica Ottino, la Eva de 1946, todavía viva y en todo su esplendor combativo; la que aún lejos del cadáver que la espera, muestra al debatir con Victoria Ocampo la fuerza que ya la ha convertido en Evita: "No hicimos una verdadera revolución. Las pruebas cantan: corremos el riesgo de tener que devolverles el poder a ustedes” (112).
} 
representada allí en 1970, y publicada en Argentina por primera vez en $2000 .{ }^{15} \mathrm{Y}$ es la de Néstor Perlongher, en su cuento “Evita vive” (1975) y en sus poemas “El cadáver”(1980) y “El cadáver de la Nación”(1989). En la obra de Copi el verdadero cadáver no es el de Eva, sino el de Perón: no sólo figuradamente por estar éste vacío, desprovisto de vida, coraje y energía (como en la clásica versión mítica del antiperonismo), sino porque ha estado efectivamente muerto antes de la acción presente. ${ }^{16}$ La obra gravita así hacia la oposición entre lo vacío (muerte) de Perón y lo lleno (vida) de Evita. Más que adherir a los significados de resurrección — habituales en las versiones hagiográficas del mito-, Copi subraya el sentido de una Eva no muerta, no enferma, sino viva; llena de energía, soberbia e impertinencia justicieras. Es la misma Eva del cuento de Perlongher, tratada como una igual por tres voces marginales que reciben de ella la dádiva más deseada (sexo, marihuana, cocaína, protección, reconocimiento o seguridad). Las tres voces mentan una fuerza asistencial sin límites para los hambrientos, ${ }^{17}$ y revelan la naturaleza (a)moral y (a)política de sus dones, que al no depender de las buenas costumbres, de los asuntos públicos o de la lealtad ideológica, ya no son dádiva sino intercambio, transfusión recíproca: el paria necesitado recibe su ración de manos de Eva; de manos del deseoso, a su vez, recibe Eva su propia energía (su goce, por ejemplo, al ayudar a gozar al "marica”: 192). Evita vive para desmitificar la solemnidad hagiográfica; de la misma manera, "Evita vive” es un texto escrito para deconstruir el fetichismo literario del cadáver. Es por eso que en el poema "El cadáver” Perlongher trabaja desde el deseo de acabar con su muerte, ${ }^{18} \mathrm{y}$ en “El cadáver de la Nación” el fin de su existencia errante no es una Eva “cadáver” sino la peligrosa encarnación de una energía viva y futura. ${ }^{19}$

${ }^{15}$ La obra de Copi (Raúl Damonte, 1939-1987) muestra a Eva en sus últimos días y lo hace con un giro sorprendente: con la ayuda de su hermano, Eva asesina a la devota enfermera que la atendía, se disfraza con su uniforme y huye, dejando en su lugar el cadáver disfrazado "de Eva”.

${ }^{16}$ Le informa Ibiza (Juan Duarte) a Perón: “¿Sabés que has estado muerto? ¿Sabés que pasaste dos años encerrado en tu escritorio completamente muerto, con un negro que te espantaba las moscas con un abanico? ¿Sabés al menos cuándo es que te moriste, en qué momento?” (157). Eva, el verdadero cadáver histórico, cierra la obra comunicando a personajes y espectadores que su enfermedad ha sido una mentira (le dice a Ibiza: "El cáncer fue idea tuya. No sé cómo explicarlo, pero estoy segura de que fue tu idea. A mí no se me hubiera ocurrido inventar semejante enfermedad” 165).

${ }^{17}$ Dice su voz fantasmagórica: “Grasitas, grasitas míos, Evita lo vigila todo, Evita va a volver por este barrio y por todos los barrios para que no les hagan nada a sus descamisados” (193-4).

${ }^{18}$ Se lee, casi en el centro matemático del poema, la siguiente pregunta retórica: "¿Y si no nos tomáramos tan a pecho su muerte, digo? / ¿ ¿si no nos riéramos entre las colas / de los pasillos y las bolas / las olas donde nosotras / no quisimos entrar / en esa noche de veinte horas / en la inmortalidad / donde ella entraba..." (versos 47-54). El juego irreverente de sentidos (colas: filas y traseros), y de rimas (bolas / olas), funciona por antífrasis para destacar el peso de la pregunta retórica inicial, que propone devaluar la muerte de Evita, que plantea desterrar (también del corpus) su muerte.

${ }^{19}$ Véase: “...el cadáver ... se ha tornado peligroso porque ella desde lo alto viene a tirar los hilos del títere o las gomas que la atan a la falsa histeria traicionada de su rictus en la impotencia de su involuntario errar” (206). En “Joyas macabras”, la reseña que escribió acerca del libro de Horacio González sobre Eva Perón, Perlongher la considera como “ala izquierda” en el espectro político: usados por sectores ultras para vencer a la burocracia dirigente peronista, el desorden, el delirio que Evita representaba fueron "tan seductores como macabros sus resultados: en el fondo de este 
Osvaldo Lamborghini muere en 1985, Copi en 1987, Perlongher en 1992; los tres escriben entre los sesenta y los ochenta. Son, sin embargo, “escritores del noventa” porque es entonces cuando ingresan en el canon y en la pugna del campo literario, ${ }^{20}$ especialmente por los textos en que revisan las hablas del mito peronista, invirtiendo los códigos o borrando las diferencias con una escritura de mezcla que es en muchos sentidos la marca de una época que propicia los cruces y los desplazamientos discursivos. Si desde la década previa la ficción se había escrito incorporando el registro de la crítica (como en el epítome Respiración artificial), la crítica de los noventa se escribe desde la ficción, mezclando sus registros como Josefina Ludmer en sus “relatos” de El cuerpo del delito, Beatriz Sarlo en sus "historias de vida” de La máquina cultural, o el Borges que propone leer la crítica como un texto de ficción en El idioma de los argentinos (de 1928, pero reeditado sesenta años más tarde: no por casualidad en los noventa). En La máquina cultural Sarlo narra a Victoria Ocampo como un espacio donde un conflicto fundamental de la cultura argentina —la mezcla de lenguajes propios y ajenos—, se cristaliza en la figura de la traductora. Y es en ese ámbito inestable de mixturas y pasajes — la traducción—, o en la articulación oximorónica de lenguajes diferentes, donde la crítica de los noventa busca situar, tras las huellas de Borges, las operaciones básicas de la literatura argentina. ${ }^{21}$ Las ficciones de los más jóvenes también suelen ser contadas desde varios registros a la vez, en un entrecruzamiento que disloca tanto el acto de emisión como el de recepción, armando reescrituras y lecturas de las fórmulas de la gauchesca y del surrealismo, del realismo crítico y el realismo mágico, de la literatura fantástica y del relato paródico. ${ }^{22}$ Estos registros de mezcla y deslizamiento se abren claramente a la percepción en la lengua lírica de la década, donde hay un asiduo trabajo con la figura de la hipálage para fijar corrimientos de sentido ejercidos como nuevo estilo "ideológico", como nuevas articulaciones de literatura y política que resplandecen más en la poesía que en la ficción. ${ }^{23}$

corredor hay un cadáver” (202). Según Perlongher, el cadáver fue una invención de Perón y el peronismo para controlar políticamente al pueblo que se pretendía liberar; es por eso que el mito de Evita se asienta sobre una "rigidez cadavérica" (202).

${ }^{20}$ Sus primeras obras ya inconseguibles, y las inéditas, son publicadas entre fines de los ochenta y los noventa: las novelas y cuentos de Osvaldo Lamborghini (con prólogo de César Aira) en Barcelona en 1988; varias obras de Copi en 1993, 1998 y 2000; los poemas y ensayos completos de Perlongher en 1997 (véanse las correspondientes entradas en la bibliografía).

${ }^{21}$ Sobre el papel de la traducción véase de Jorge Panesi, Críticas, especialmente el capítulo "La traducción argentina”. Sobre la fusión oximorónica, el capítulo “XXXX” en La chancha con cadenas, de Daniel Link.

${ }^{22}$ Un par de ejemplos: en su segunda novela, El sueño del señor juez (2000), Carlos Gamerro reescribe el Martín Fierro en clave onírico-absurda conectada con la línea textual que va de Osvaldo Lamborghini al primer César Aira; Se esconde tras los ojos, primera novela de Pablo Toledo (Premio Clarín 2000) acomete la tensión trágico-cómica de la Argentina menemista con un doble registro de parodia y realismo.

${ }^{23}$ Según la definición de Marchese y Forradelas, la hipálage "es una figura sintáctica o semántica que consiste en atribuir a un objeto el acto o la idea que conviene a un objeto cercano” (197). Entre otros libros importantes de la década, son ejemplos del uso "ideológico" de la hipálage El guadal, de Daniel García Helder, o Puentes, de Alicia Genovese. En muchos de estos poemas se reconecta lo disímil (el cartonero y el rapsoda; el caso policial y la tradición del Cancionero de Baena; Venecia 
Reaparece así en la narrativa argentina de los noventa la fuerte tradición de los tránsitos semánticos alusivos o alegóricos que habían sido característicos en la literatura producida durante la dictadura; pero ahora esta tradición está conectada con otras expectativas escriturales: no existe para decir lo indecible-prohibido, como a fines de los setenta, sino para articular lo que es indecible porque aún no tiene nombre. Ya no se trata de revelar un sentido que se sabe ausente, sino de producir un sentido que se ignora o cuya existencia es incierta; no se intenta conectar un relato de hospital o de frontera con la noción cierta del terror o la tortura, sino conectar el cadáver de Evita con el decir oscuro de los mitos populares, o reunir la circulación incesante de relatos que hace la máquina narrativa de Macedonio con la política oficial de olvido que ha clausurado las ilusiones redemocratizadoras (en La ciudad ausente, el segundo epítome de Piglia). Si el recurso setentista de la alegoría implicaba referir el significado a un código oculto de mayor importancia semántica, la estrategia alegórica típica de los noventa es la que pone en contacto dos zonas de igual rango cuyos elementos (los de la alegoría y los del sentido "recto" o “serio") se corresponden en igualdad semántica. ${ }^{24}$ La tradición estética de mezcla que arranca desde Puig ha impuesto sus condiciones a la década: tanto el discurso "de superficie” como el oculto de referencia poseen el mismo valor semántico; el desciframiento del enigma funciona entonces en ambas direcciones y esa mezcla resulta en un desplazamiento de escritura y lectura: desde practicar la descodificación, a permanecer en la incógnita; desde buscar una respuesta, a perdurar en la pregunta. En La pesquisa (1994) de Saer — cuyo título mismo compendia esta tensión escritural de la época—, el enigma del asesino serial posee el mismo rango que el enigma del discurso que lo indaga; si la verdad del crimen es incierta (lo “fictivo"), también lo es la verdad del relato que lo cuenta (lo "real”), y la única certidumbre reside en la conversación misma, que ayuda a los personajes a olvidar por un momento el "tiempo inquietante y oscuro que los atraviesa". Publicada en el momento de máximo esplendor de la era menemista, la lectura alegórica (política) de La pesquisa no consistió en conectar la época con el crimen, sino con el sentido de ambigüedad y de interrogación incierta: una conversación de palabras borrosas sobre un enigma igualmente confuso, cuyo valor consiste en hacer perdurar la indagación y la pregunta, persistentemente, en medio de la perplejidad cotidiana.

Es desde esta perspectiva que los relatos del noventa hacen una lectura política del fracaso de esa misma clase media que produce y consume literatura. Enmarcada entre 1989 — la hiperinflación y el fin de las esperanzas depositadas en la redemocratización-y diciembre de 2001 —cuando finalmente se desmorona el sistema impuesto durante la década-, la clase media argentina tuvo en sus narradores un relato político-alegórico de su crisis a medida que ésta se iba desarrollando. Son textos (no sólo narrativos) que pueden ser leídos como un hipotético architexto conjunto, independientemente de los sistemas

o Mississipi y el Riachuelo), en paisajes degradados, barrios empobrecidos y fábricas desmanteladas del noventa. Según Panesi, "si tuviera que decir cuatro o cinco frases que la literatura ha producido sobre [lo político], no creo encontrarlas en ninguna novela [...] y sí en frases, versos, palabras de Perlongher" (Rinesi 26).

${ }^{24}$ De acuerdo con Quintiliano, según Lausberg, es una clase de alegoría “en la que la correspondencia de los elementos particulares [de la alegoría] con los elementos particulares del sentido recto no exige una transferencia imaginativa” (II: 286, parágrafo 898). 
individuales de significación que lo componen; relatos de alegoría blanda, con sus dos espacios constitutivos dispuestos en igualdad semántica (y por lo tanto no opuestos, según lo requerido por la tradición puiguiana de mezcla), cuya lectura es política porque procura desplegar (entender) los noventas menemistas. ${ }^{25}$ En su película Gatica (1993), a Leonardo Favio no le interesa la historia del boxeador o del primer peronismo sino el "fracaso de la Nación argentina, la pérdida de sus sueños de soberanía, independencia y libertad; [la película] es un puro ideograma de nuestra derrota” (Ure 12). Como La pesquisa de Saer, Gatica es un texto que en pleno apogeo menemista lo examina como tiempo "inquietante y oscuro”, con síntomas de caída y ruptura (al igual que otros textos de la década, Favio explora además la muerte de Eva como fuente de fuerza y apertura). Los nuevos pobres de la década aparecen en los desesperanzados pícaros urbanos de Jorge Stamadianos en Latas de cerveza en el Río de la Plata (1995); en los rebeldes disidentes de Marcelo Cohen en El Testamento de O'Jaral (1995); en los chicos desharrapados de Andrés Rivera en Tierra de exilio (2000). El architexto también está saturado de una pobreza sin referencia temporal precisa: los indigentes rurales que irrumpen en la paz bucólica, en Cita en Marruecos (1996) de Rodolfo Rabanal; la clase media arruinada en Hotel Edén (1999), de Luis Gusmán; los miserables obreros en Boca de lobo (2000), de Sergio Chejfec.. ${ }^{26}$ Como en los relatos escritos durante la dictadura, un significado monológico y unívoco que no admite diferencias es el enemigo. Pero la supremacía del modo "occidental y cristiano" de 1976-83 ha sido reemplazada en los noventa por la "razón de los mercados”, y es contra esa homogeneidad de sentido que los relatos proponen una circulación incesante de discursos, un fluir permanente de lo distinto. Para proteger el recuerdo social de la trivialización que pretende imponerle el poder político, la máquina narrativa de Macedonio imaginada por Piglia renueva sin cesar la circulación de relatos múltiples y variados que hace posible pensar otra vez lo utópico. En El Testamento de O’Jaral, el control discursivo del poder "globalizador" es desafiado por rebeldes cuyo lenguaje y consignas (residuales de los setenta) sólo por existir hacen temblar la homogeneidad del sistema.

\footnotetext{
${ }^{25}$ Las dos presidencias de Carlos Menem (1989-95 y 1995-99) y la abortada presidencia de Fernando de la Rúa (1999-2001) sellan la hegemonía del proyecto político-económico neoliberal de ajuste que, patrocinado por los organismos internacionales, impuso la primacía de los "mercados” por encima del concepto de Estado. Los resultados visibles del proyecto fueron la enorme concentración de beneficios para los grupos transnacionales relacionados con el poder político, la distribución regresiva del ingreso y la consiguiente precarización y desigualdad social. A fines de la etapa, la situación social era devastadora; la "producción de pobreza" neoliberal (Vilas 946) resultaba en grandes sectores de población por debajo del nivel de subsistencia y en altísimos porcentajes de desempleo y subempleo. Al iniciarse la democracia en diciembre de1983, la deuda nacional era de 17.000 millones de dólares; en diciembre de 2001, se estimaba en unos 135.000 millones.

${ }^{26}$ Así como en la producción de Chejfec es visible la gradual presencia de lo político-social, sobre todo a partir de su novela El aire (ver Saavedra; y Sarlo, "El amargo corazón del mundo”), en la obra de Gusmán también se advierte esa creciente presencia. Refiriéndose a la factura de Hotel Edén, Gusmán subrayó la presión de lo político sobre su escritura: “No quisiera que cierta posición crítica respecto de determinado momento histórico-político llevara agua para un molino que no me interesa, que puede ser el descompromiso o la despolitización. Ahí hay que ser muy cuidadoso” (Costa 6).
} 
Y también como en las ficciones escritas durante y después de la dictadura, la memoria fue en los noventa un núcleo semántico de resistencia. Para oponerse al discurso pacificador “de reconciliación y olvido” impulsado por los sectores hegemónicos, muchos relatos de la década trabajaron la ficción histórica según la tradición alusivo-alegórica de los textos que regresan al pasado para decir el presente. ${ }^{27}$ Pero el rasgo distintivo de esta escritura fue la incomodidad para practicarla, como en El informe (1997) de Martín Kohan, texto armado con discursos en cajas chinas en que la digresión novelesca que había hecho Mitre durante su relato del cruce de los Andes origina otra digresión literaria en el informe histórico que alguien está escribiendo por encargo en el siglo veinte, y ésta, a su vez, induce una tercera digresión sobre los cruces de historiografía y ficción (cómo escribir historia e Historia, y sobre todo, cómo escribir con y sobre la Historia). De la misma manera, los relatos históricos más provocativos de la década desplazan sus modos alusivoalegóricos a referencias de segundo grado, como si se sintiera que el recurso de usar un pasado nacional "verdadero" para decir el presente estuviera ya retóricamente exhausto. Para lograr esta referencialidad oblicua se crearon historias de culturas "otras” totalmente imaginarias, que funcionan como lo hace el pasado “real” de los relatos históricos clásicos: en Los zumitas (1999) de Federico Jeanmaire es una civilización entre los ríos Eufrates y Tigris, contemporánea a los asirios y babilonios; en La historia (1999) de Martín Caparrós es una perdida cultura de los Valles Calchaquíes. Es posible leer a los zumitas como un trabajo por antítesis sobre la cultura argentina de los noventa; es posible leer el ficticio manuscrito calchaquí — anotado y publicado en la década del setenta por un apócrifo investigador argentino- - como un relato de origen descodificable a partir de la exangüe experiencia política de los noventa. ${ }^{28}$ Memoria y alegoría cierran así el siglo narrativo argentino, acaso como únicas construcciones de certeza en medio de una clara descomposición de "lo real”.

\footnotetext{
${ }^{27}$ La novela histórica fue escrita y consumida profusamente en los noventa, especialmente en versiones bestseller, light sobre las hazañas y amoríos de personajes del pasado argentino o americano (ejemplos paradigmáticos son las novelas de María Esther de Miguel, como El general, el pintor y la dama, Premio Planeta 1996, o Las batallas secretas de Belgrano, Premio de los Libreros 1996). La novela histórica light se vendió muy bien hasta fines de la década, pero fueron unánimemente devaluadas dentro del campo literario por rutinarias y formulaicas. Muchos otros relatos históricos mantuvieron sin embargo un alto nivel de calidad literaria e ingresaron por ello en el debate ideológico-escritural de la década. Entre ellos, sobre el siglo diecinueve: Santo oficio de la memoria (1991) de Mempo Giardinelli, La pasión de los nómades (1994) de María Rosa Lojo, El farmer (1996) y La lenta velocidad del coraje (cuentos: 1998) de Andrés Rivera; sobre 1919: El profundo sur (1999) de Rivera; sobre los sesenta: Claudia conversa (1995) de David Viñas; sobre los setenta: Villa (1996) de Luis Gusmán, La historia (1999) de Martín Caparrós; sobre 1976-83: Las islas (1998) de Carlos Gamerro, Sangre de cualquier grupo (1996) de Vicente Muleiro, Los juegos siniestros argentinos (1996) de Mirta Maidana, El árbol de la gitana (1997) de Alicia Dujovne Ortiz, Un secreto para Julia (2000) de Patricia Sagastizábal; sobre la etapa de redemocratizaión: Tela de juicio (1991) de Leonardo Moledo; sobre los noventa menemistas: Frivolidad (1995) de Juan Forn, Se esconde tras los ojos (2000) de Pablo Toledo.

${ }^{28}$ Véanse en Costa (“Curiosas criaturas noveladas"), y en Sifrim y en Chiaravalli, las declaraciones de Jeanmaire y Caparrós sobre esta intención escritural de referencia.
} 
Borges, Jorge Luis. El idioma de los argentinos. [1928]. Buenos Aires: Seix Barral, 1994. “Tlön, Uqbar, Urbis Tertius” [1941]. Obras completas. Buenos Aires: Emecé, 1974. 431-43.

“La postulación de la realidad” [1927]. Obras completas. Buenos Aires: Emecé, 1974. 217-21.

Caparrós, Martín. La historia. Buenos Aires: Norma, 1999.

Cohen, Marcelo. El testamento de O’Jaral. Madrid: Anaya, 1995.

Copi (Raúl Damonte). Una visita inoportuna. Colección Las obras y sus puestas 3. Buenos Aires: Teatro Municipal General San Martín: 1993.

Habla Copi: homosexualidad y creación. José Tcherkaski, ed. Buenos Aires: Galerna, 1998.

Eva Perón (1970). Jorge Monteleone, trad. Buenos Aires: Adriana Hidalgo Editora, 2000.

Cortázar, Julio. Bestiario. Madrid: Alfaguara, 1982.

Costa, Flavia. “Luis Gusmán. El paraíso de los amores perdidos”. Clarín (Buenos Aires, 4 de julio de 1999): Cultura y Nación 4-7.

“Curiosas criaturas noveladas. Entrevista con Martín Caparrós”. Clarín (Buenos Aires, 24 de octubre de 1999): Cultura y Nación 6-7

Chejfec, Sergio. “Narrativa: el capítulo que se viene. Respuesta al cuestionario”. Tiempo Argentino (Buenos Aires, 6 de noviembre de 1983): Cultura 5. El aire. Buenos Aires: Aguilar-Alfaguara, 1992. Boca de lobo. Buenos Aires: Alfaguara, 2000.

Chiaravalli, Verónica. “Inventar una civilización. Entrevista a Martín Caparrós”. La Nación (Buenos Aires, 4 de abril de1999), Sección 6: 8.

De Miguel, María Esther. Las batallas secretas de Belgrano. Buenos Aires: Seix Barral, 1995.

El general, el pintor y la dama. Buenos Aires: Planeta, 1996.

Dujovne Ortiz, Alicia. El árbol de la gitana. Buenos Aires: Alfaguara, 1997.

Echeverría, Esteban y Nélida Salvador. El matadero y otras prosas. Buenos Aires, 1975. Figueras, Marcelo. El muchacho peronista. Buenos Aires: Planeta, 1991.

Fogwill, Rodolfo. Una pálida historia de amor. Buenos Aires: Planeta, 1991.

Forn, Juan. Frivolidad. Buenos Aires: Planeta, 1995.

Fresán, Rodrigo. "El único privilegiado”. Historia argentina. Buenos Aires: Planeta, 1991. 43-8

Gamerro, Carlos. Las islas. Buenos Aires: Simurg, 1998. El sueño del señor juez. Buenos Aires: Sudamericana, 2000.

García Helder, Daniel. El guadal. Buenos Aires: Libros de Tierra Firme, 1994.

Genovese, Alicia. Puentes. Buenos Aires: Libros de Tierra Firme: 1999.

Giardinelli, Mempo. Santo oficio de la memoria. Barcelona: Norma, 1991.

Gusmán, Luis. En el corazón de junio. Buenos Aires: Sudamericana, 1983. Villa. Buenos Aires: Sudamericana, 1995. Hotel Edén. Buenos Aires: Norma, 1999. 
Jeanmaire, Federico. Los zumitas. Buenos Aires: Norma, 1999.

Kohan, Martín. El informe. San Martín y el otro cruce de los Andes. Buenos Aires: Sudamericana, 1997.

Lamborghini, Leónidas. "Eva Perón en la hoguera” (1972). Las reescrituras. Buenos Aires: Ediciones del Dock, 1996. 61-78.

Lamborghini, Osvaldo. “El niño proletario”. Sebregondiretrocede. Buenos Aires: Ediciones Noé, 1973. 61-9. Novelas y cuentos. Barcelona: Ediciones del Serbal, 1988.

Lausberg, Heinrich. Manual de retórica literaria. Fundamentos de una ciencia de la literatura (1960). Biblioteca Románica Hispánica. Manuales 15. 3 tomos. Madrid: Gredos, 1966-1968.

Link, Daniel. La chancha con cadenas. Doce ensayos de literatura argentina. Buenos Aires: Ediciones del Eclipse, 1994.

Lojo, María Rosa. La pasión de los nómades. Buenos Aires: Atlántida, 1994.

Ludmer, Josefina. El cuerpo del delito. Un manual. Buenos Aires: Perfil, 1999.

Maidana, Mirta. Los juegos siniestros argentinos. Buenos Aires: Corregidor, 1996.

Marchese, Angelo y Joaquín Forradelas. Diccionario de retórica, crítica y terminología literaria. Barcelona: Ariel, 1986.

Martínez, Tomás Eloy. La novela de Perón. Buenos Aires: Legasa, 1987. Santa Evita. Buenos Aires: Planeta: 1995.

Martini, Juan. La vida entera. Barcelona: Bruguera, 1981. La construcción del héroe. Buenos Aires: Legasa, 1989.

Martini Real, Juan Carlos. Copyright. Buenos Aires: Sudamericana, 1979.

Moledo, Leonardo. Tela de juicio. Buenos Aires: Cántaro, 1991.

Moyano, Daniel. El vuelo del tigre. Madrid: Legasa, 1981.

Muleiro, Vicente. “Daniel Guebel. La realidad es la literatura”. Sur (Buenos Aires, 22 julio de 1990): 26. Sangre de cualquier grupo. Buenos Aires: Schprejer-Futuro, 1996.

O’Donnell, María. “Encuentro de escritores argentinos en Pinamar. Vamos a la playa”. Página 12 (Buenos Aires, 1 de diciembre de 1991): Primer Plano 7.

Ottino, Mónica. Evita y Victoria. Comedia patrótica en tres actos. Buenos Aires: Grupo Editor Latinoamericano, 1990.

Panesi, Jorge. Críticas. Buenos Aires: Norma, 2000.

Pauls, Alan. Manuel Puig: La traición de Rita Hayworth. Biblioteca Crítica Hachette 7. Buenos Aires: Hachette, 1986.

Perlongher, Néstor. Poemas completos. Roberto Echevarren, ed. Buenos Aires: Seix Barral, 1997.

Prosa plebeya. Ensayos 1980-1992. Christian Ferrer y Osvaldo Baigorria, eds. Buenos Aires: Colihue, 1997.

"El cadáver” [1980]. Poemas completos. Roberto Echevarren, ed. Buenos Aires: Seix Barral, 1997. 42-5.

“El cadáver de la Nación” [1989]. Poemas completos. Roberto Echevarren, ed. Buenos Aires: Seix Barral, 1997. 177-83. 
“Evita vive” [1975] . Prosa plebeya. Ensayos 1980-1992. Christian Ferrer y Osvaldo Baigorria, eds. Buenos Aires: Colihue, 1997. 191-5.

“Joyas macabras” [1990]. Prosa plebeya. Ensayos 1980-1992. Christian Ferrer y Osvaldo Baigorria, eds. Buenos Aires: Colihue, 1997. 203-207.

Piglia, Ricardo. Respiración artificial. Buenos Aires: Pomaire, 1980. La ciudad ausente. Buenos Aires: Sudamericana, 1992.

Puig, Manuel. La traición de Rita Hayworth. Buenos Aires: Jorge Álvarez, 1968.

Rabanal, Rodolfo. Cita en Marruecos. Buenos Aires: Seix Barral, 1996.

Rinesi, Eduardo. “A mazazo limpio. Diálogo con Eduardo Grüner, Jorge Panesi y Américo Cristófalo”. El ojo mocho 15 (Buenos Aires, 2000): 19-35.

Rivera, Andrés. El farmer. Buenos Aires: Alfaguara, 1996. La lenta velocidad del coraje. Buenos Aires: Alfaguara, 1998. El profundo sur. Buenos Aires: Alfaguara, 1999. Tierra de exilio. Buenos Aires: Alfaguara, 2000.

Rozenmacher, Germán. Cabecita negra. Buenos Aires: Ediciones de la Flor, 1997.

Saavedra, Guillermo. “Un mundo extrañado”. Reseña de Boca de lobo de Sergio Chejfec. La Nación (Buenos Aires, 8 de octubre de 2000): $6^{\text {ta }}$ sección 7.

Saer, Juan José. Nadie nada nunca. México: Siglo XXI, 1980. La pesquisa. Buenos Aires: Seix Barral, 1994.

Saccomano, Guillermo. Roberto y Eva. Buenos Aires: Legasa, 1989.

Sagastizábal, Patricia. Un secreto para Julia. Buenos Aires: Sudamericana, 2000.

Sarlo, Beatriz. La máquina cultural. Maestras, traductores y vanguardistas. Buenos Aires: Ariel, 1998.

“El amargo corazón del mundo”. Reseña de Boca de lobo de Sergio Chejfec. Clarín (Buenos Aires, 5 de noviembre de 2000): Cultura y Nación 10.

Shúa, Ana María. Soy paciente. Buenos Aires: Losada, 1980.

Sifrim, Mónica. “La Historia, esa impúdica ambición. Entrevista con Martín Caparrós”. Clarín (Buenos Aires, 4 de abril de 1999): Cultura y Nación 10-11.

Stamadianos, Jorge. Latas de cerveza en el Río de la Plata. Buenos Aires: Emecé, 1995.

Szichman, Mario. A las 20:25 la señora entró en la inmortalidad. Hanover, NH: Ediciones del Norte, 1981.

Toledo, Pablo. Se esconde tras los ojos: o las desventuras de un joven fotógrafo y el singular grupo que con él se relaciona. Buenos Aires: Arte Gráfico, 2000.

Ure, Alberto. "Gatica y el fracaso de la nación argentina”. Clarín (Buenos Aires, 24 de junio de 1993): Cultura y Nación 12

Ventura, Any. "Todo lo que no es química es política. Diálogo con el narrador José Pablo Feinmann”. Clarín (Buenos Aires, 12 de agosto de 1982): Cultura y Nación 2-3.

Vilas, Carlos María. "De ambulancias, bomberos y policías: la política social del neoliberalismo”. Desarrollo económico 144 (Buenos Aires, 1997): 931-52.

Viñas, David. "La señora muerta”. Las malas costumbres. Buenos Aires, Editorial Jamcana, 1963. 63-72.

Claudia conversa. Buenos Aires: Planeta, 1995.

Walsh, María Elena. “Eva”. Cancionero contra el mal de ojo. Buenos Aires: Sudamericana, 1976. 93-5. 
Walsh, Rodolfo. “Esa mujer” (1965). Obra literaria completa. México: Siglo XXI, 1981. 163-71.

Warley, Jorge. "Los de treinta y pico. Abran cancha”. El porteño (Buenos Aires, 19 setiembre de 1990): 37-9. 